\title{
Multiple Slip Impact on the Darcy-Forchheimer Hybrid Nano Fluid Flow Due to Quadratic Convection Past an Inclined Plane
}

\author{
Fouad Othman Mallawi and Malik Zaka Ullah *(D) \\ Department of Mathematics, Faculty of Science, King Abdulaziz University, Jeddah 21589, Saudi Arabia; \\ fmallawi@kau.edu.sa \\ * Correspondence: malikzakas@gmail.com or zmalek@kau.edu.sa
}

Citation: Mallawi, F.O.; Ullah, M.Z. Multiple Slip Impact on the Darcy-Forchheimer Hybrid Nano Fluid Flow Due to Quadratic Convection Past an Inclined Plane. Mathematics 2021, 9, 2934. https:/ / doi.org/10.3390/math9222934

Academic Editors: Muhammad Hamid and Wei Wang

Received: 6 October 2021

Accepted: 15 November 2021

Published: 18 November 2021

Publisher's Note: MDPI stays neutral with regard to jurisdictional claims in published maps and institutional affiliations.

Copyright: (c) 2021 by the authors. Licensee MDPI, Basel, Switzerland. This article is an open access article distributed under the terms and conditions of the Creative Commons Attribution (CC BY) license (https:// creativecommons.org/licenses/by/ $4.0 /)$.

\begin{abstract}
Nowadays, the problem of solar thermal absorption plays a vital role in energy storage in power plants, but within this phenomenon solar systems have a big challenge in storing and regulating energies at extreme temperatures. The solar energy absorber based on hybrid nanofluids tends to store thermal energy, and the hybrid nanofluids involve the stable scattering of different nano dimension particles in the conventional solvent at a suitable proportion to gain the desired thermophysical constraints. The authors focus on the behavior of the inclined plate absorber panel as the basic solution of water is replaced by a hybrid nanofluid, including $\mathrm{Cu}$ (Copper) and $\mathrm{Al}_{2} \mathrm{O}_{3}$ (Aluminum Oxide), and water is utilized as a base surfactant in the current investigation. The inclined panel is integrated into a porous surface with the presence of solar radiations, Joule heating, and heat absorption. The fundamental equations of the flow and energy model are addressed with the similarity transformations. The homotopy analysis method (HAM) via Mathematica software is used to explore the solution to this problem. Furthermore, the important physical characteristics of the rate of heat transfer, omission and absorption of solar radiation, and its impact on the solar plant are observed.
\end{abstract}

Keywords: inclined plate; Darcy-Forchheimer flow; nanomaterials $\left(\mathrm{Cu}, \mathrm{Al}_{2} \mathrm{O}_{3}\right)$; heat source; HAM

\section{Introduction}

The importance of energy is inevitable in our lives. Researchers and engineers are focusing to introduce advanced and affordable techniques to fulfill the requirements. Solar energy resources are one of the important and cheap resources used within the energy sector. Flat panels and thermal transition solvents are used to convert sunlight into electricity. Sunlight is captured by the instruments via an absorbing panel, which transfers heat to the absorption liquid (mainly water, a water mixture, and Ethylene Glycol). Its negative aspect is the poor specific features of such ordinary solvents, which lead to bad energy properties. Mostly in the situation of fossil energy, the transition mechanism constrained their output. One of several activities that have sparked attention in recent times to improve the thermal effectiveness of such an innovation is converting standard working fluids into nanofluids. Nanofluids are sustainable emulsions of solid materials varying in size from $1 \mathrm{~nm}$ to $100 \mathrm{~nm}$ [1]. Nanofluid is also widely used for heat exchangers [2], storing solar energy [3,4], freezing mechanisms [5]. Suresh et al. [6] performed a study on synthesized hybrid nanofluids $\left(\mathrm{Al}_{2} \mathrm{O}_{3}-\mathrm{Cu} /\right.$ water). The flow of nanofluids was investigated by MebarekOudina [7] using a variety of basic fluids. Through the applications of the nanofluid, Li et al. [8] scrutinized the motion of nanofluids inside a porous conduit by applying the induced external power of the Buongiorno model. Momin [9] investigated the coupled convection in an inverted cylinder for laminar flow utilizing water- $\mathrm{Al}_{2} \mathrm{O}_{3}$ and a hybrid nanofluid. The findings of Zaim [10], Sheikholeslami [11], and Gul [12] are a few examples of scientific literature in the thermal field and energy systems that have used a theoretical and mathematical framework to handle heat transport and nanofluids. 
Hybrid nanofluids are heat transport solutions that include two forms of nanomaterials immersed in a traditional fluid (water) and are utilized in a variety of heat transportation technologies, comprising electrochemical and nanosensors, manufacturing, and monitoring. Hayat and Nadeem [13] analyzed the performance of an extending surface on the energy conversion of a hybrid nanofluid. Investigators claimed that by introducing $5 \%$ of nano components, the Nusselt parameter had been significantly enhanced. Chamkha [14] modeled and computed the modeled movement of a $\mathrm{Cu}-\mathrm{Al}_{2} \mathrm{O}_{3} / \mathrm{H}_{2} \mathrm{O}$ hybrid nanofluid into a trapezoidal vessel as a function of time. Aziz [15] and Lund [16] planned the circulation of hybrid nanofluid across a rotating plate. The $\mathrm{Al}_{2} \mathrm{O}_{3}$ nanofluids flow over a horizontal cylinder with the combination of entropy generation is investigated by Mwesigye and Huan [17]. Lund [18] explored the role of viscous dissipation on a hybrid nanofluid $\left(\mathrm{Cu}-\mathrm{Al}_{2} \mathrm{O}_{3} / \mathrm{H}_{2} \mathrm{O}\right)$ flow over a stretched surface. Sohail [19] also investigated the nanofluids' flow over a stretching surface. These materials are widely used in different industrial and engineering applications. Recently, Aladdin et al. [20] used the flow of $\mathrm{Cu}-\mathrm{Al}_{2} \mathrm{O}_{3} / \mathrm{H}_{2} \mathrm{O}$ nanofluids in the permeable medium with suction/injection applications. Kapen et al. [21], Ilyas et al. [22], and Shah [23] used $\mathrm{Cu}-\mathrm{Al}_{2} \mathrm{O}_{3} / \mathrm{H}_{2} \mathrm{O}$ nanofluids for a variety of applications.

The porous space applications may be considered in diverse areas such as environmental science, construction management, nuclear engineering, solar thermal science, and bioinformatics. Geothermal energy, chemical catalyst connections, circulation of blood in the lungs or the arteries, spongy heated tubes, and subterranean electrical wires are just a few of the operations that need fluid movement in porous space. For understanding the flow that occupies porous space, Darcy's rule is widely used. In terms of high-speed and turbulent repercussions in a porous medium, Darcy's idea is still incorrect. To modify the influence of inertia on relative permeability, Forchheimer [24] established a second-order polynomial for describing momentum. It is known as the Forchheimer factor, according to Muskat [25]. Numerous scholars studied the flow through porous media employing DarcyForchheimer principles in different geometries. Many of them will be addressed herein. Saif [26] proposed the motion of nanofluids via porous materials. Rasool [27] established the Darcy-Forchheimer nanofluid flow produced by a stretched surface. Sadiq [28] analyzed the Darcy-Forchheimer liquid motion through a spinning disc. Sheikholeslami [29] reported non-Darcy liquid within the transparent cylinder. Hayat $[30,31]$ evaluated how the Darcy-Forchheimer model and Electromagnetic-Hydrodynamic (EMHD) affected the flow of a viscous fluid. The authors further investigated how the second law of thermodynamics can be used to analyze entropy generation. Kumar [32] employed thermal radiation to estimate the statistical solution of CNT nanofluid motion in the shape of converging and diverging tubes.

Thermal/solar radiation refers to the mechanism of energy transport processes that take the form of electromagnetic fields. The larger temperature variation between the two surfaces causes this process to develop. However, several technological activities took place to gain the desired amount of energy through advanced techniques. The relevance of that kind of radiation may be observed in heat transfer, particularly in aerospace architecture, solar plants, nuclear power plants, material sciences, furnace design, and glasses manufacturing $[33,34]$. The implementation of thermal radiation for heat transfer is illustrated in [35] with similar importance. Bilal [36] examined the effect of electromagnetichydrodynamic (EMHD) waves on a micro-polar fluid flow over a stretchable surface. Different scholars have examined a range of aspects for such a topic (see [37,38]).

The current study examines the effects of heat source, Darcy-Forchheimer model, radiation, and $\left(\mathrm{Cu}\right.$, and $\left.\mathrm{Al}_{2} \mathrm{O}_{3}\right)$ nanomaterials on the heat exchange rate and movement of $\mathrm{H}_{2} \mathrm{O}$ as a common solvent, as well as its applications in enhancing the efficiency of inclined plate solar panels. The governing expression of heat is determined when viscous dissipation, Joule heating, and thermal radiation are taken into account. The HAM technique was utilized to evaluate the hybrid and nanofluid flows situation, which was based on differential equations. The thermal and velocity profiles are used to describe the assessment 
of several significant factors. The suggested quantitative outcomes of the present study are equated to prior published results for validation purposes.

\section{Mathematical Modeling}

The two-dimensional, time-dependent flow of water-based hybrid nanofluids (a composition of $\mathrm{Al}_{2} \mathrm{O}_{3}$ and $\mathrm{Cu}$ ) has been considered on an inclined plate. The inclined plate makes an angle $\theta$ with the vertical axis. The inclined plate in the shape of a solar panel is drawn in Figure 1. The Darcy-Forchheimer porous space is used in the mathematical model. The sheet surface is stretched with velocity $U_{w}=\frac{b x}{(1-\alpha t)}, a>0$ along the x-axis as shown in the geometry.

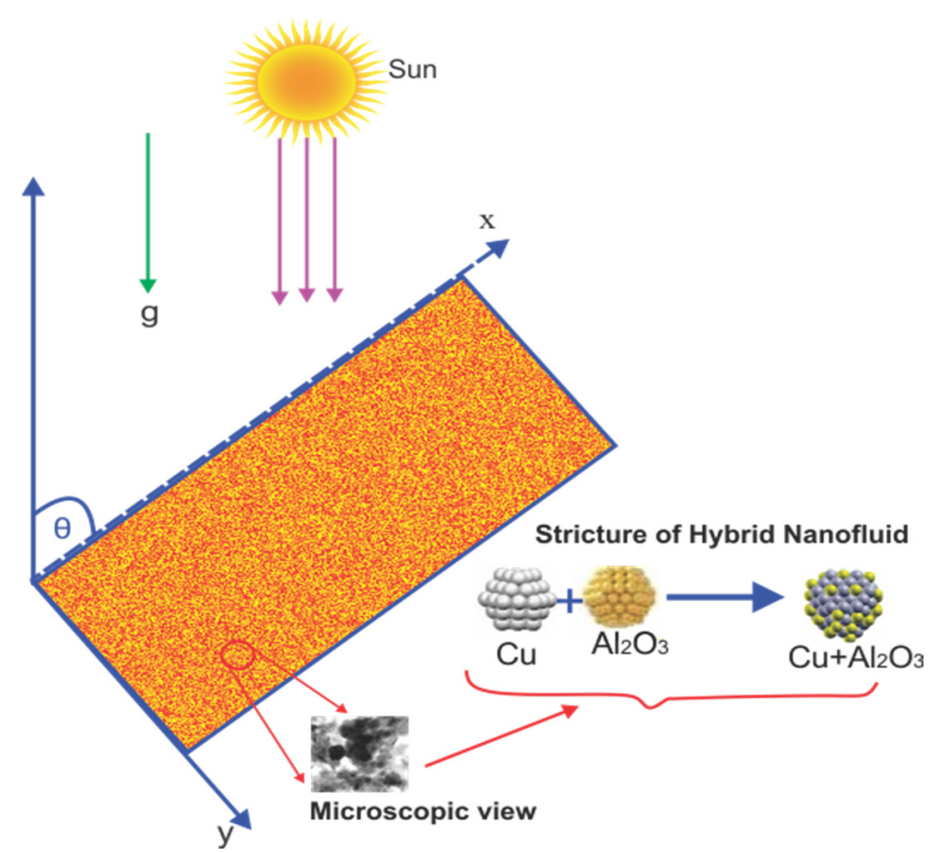

Figure 1. Solar collector schematic model.

The stable dispersion of the solid materials $\left(\mathrm{Cu}\right.$ and $\left.\mathrm{Al}_{2} \mathrm{O}_{3}\right)$ and base fluid $\left(\mathrm{H}_{2} \mathrm{O}\right)$ is considered with slip physical conditions. In addition, energy formulation takes into consideration Joule heating, thermal radiation, and viscous dissipation. Moreover, $T_{w}$ is the temperature of the wall and $T_{\infty}$ the free stream. The basic governing equations for the Darcy-Forchheimer flow are written as.

$$
\frac{\partial u}{\partial x}+\frac{\partial v}{\partial y}=0
$$

$$
\frac{\partial u}{\partial t}+u \frac{\partial u}{\partial x}+v \frac{\partial u}{\partial y}=v_{h n f}\left(\frac{\partial^{2} u}{\partial y^{2}}\right)-\frac{1}{\rho_{h n f}} F_{0} u^{2} \pm g\left[\beta_{h n f}\left(T-T_{\infty}\right)+\beta_{h n f}^{2}\left(T-T_{\infty}\right)^{2}\right] \operatorname{Cos} \theta-\frac{v_{h n f}}{K} u,
$$

$$
\left(\frac{\partial T}{\partial t}+u \frac{\partial T}{\partial x}+v \frac{\partial T}{\partial y}\right)=\frac{k_{h n f}}{(\rho C p)_{h n f}} \frac{\partial T^{2}}{\partial y^{2}}+\frac{\mu_{h n f}}{(\rho C p)_{h n f}}\left(\frac{\partial u}{\partial y}\right)^{2}+\frac{16}{3(\rho C p)_{h n f}}\left(\frac{\sigma^{*} T_{\infty}^{3}}{k^{*}} \frac{\partial^{2} T}{\partial y^{2}}\right)+\frac{1}{(\rho C p)_{h n f}} Q_{0}\left(T-T_{\infty}\right)
$$

The permissible boundary conditions are

$$
\begin{gathered}
u=\mu_{h n f}\left(\frac{\partial u}{\partial y}\right)+u_{w}, v=0, \quad-k_{0}\left(\frac{\partial T}{\partial y}\right)=h\left(T-T_{w}\right), \quad \text { at } y=0, \\
u=0, \quad v=0, \quad T \rightarrow T_{\infty}, \quad \text { at } \quad y \rightarrow \infty .
\end{gathered}
$$

Equation (1) concerns continuity, Equation (2) is about momentum, and Equation (3) stands for energy. The convection term is considered quadratic (nonlinear). The positive $g$ 
stand for the gravity force along the downward direction, whereas the negative $g$ shows the contrasting force occurs due to opposite stretching against the gravity. Here, $u, v$ are the velocity components along the $\mathrm{x}$ and $\mathrm{y}$-directions, respectively. $K$ is the porous surface parameter, $F_{0}=\frac{C_{b}}{K^{\frac{1}{2}}}$ is the non-uniform Inertia coefficient, $C_{b}$ is the positive constant, and $Q_{0}$ is the rate of heat generation/absorption. $\beta_{\text {hnf }}$ is the thermal expansion coefficient of the hybrid nanofluids; $v_{h n f}$ is the kinematic viscosity of the hybrid nanofluids. Here, the nanomaterial volume fraction $\mathrm{Cu}$ is symbolized by $\phi_{\mathrm{Cu}}$, whereas $\phi_{\mathrm{Al}_{2} \mathrm{O}_{3}}$ indicated the $\mathrm{Al}_{2} \mathrm{O}_{3}$ nanoparticle.

The subscript $h n f$ denotes the hybrid nanofluid, $n f$ denotes nanofluid, and $f$ denotes base fluid in Table 1 . The thermophysical numerical values of the $\mathrm{Al}_{2} \mathrm{O}_{3}, \mathrm{Cu}$, and water are displayed in Table 2 from the existing literature.

Table 1. Mathematical Models of thermophysical properties.

\begin{tabular}{|c|c|}
\hline Nanofluid & Hybrid Nanofluid \\
\hline$\rho_{n f}=\left(1-\phi_{C u}\right) \rho_{f}+\phi_{C u} \rho_{C u}$ & $\rho_{\text {hnf }}=\left\{\left(1-\phi_{\mathrm{Al}_{2} \mathrm{O}_{3}}\right)\left[1-\phi_{\mathrm{Cu}}\right] \rho_{n f}+\phi_{\mathrm{Cu}} \rho_{\mathrm{Cu}}\right\}+\phi_{\mathrm{Al}_{2} \mathrm{O}_{3} \rho_{\mathrm{Al}_{2} \mathrm{O}_{3}}}$ \\
\hline$(\rho \beta)_{n f}=\left(1-\phi_{C u}\right)(\rho \beta)_{f}+\phi_{C u}(\rho \beta)_{C u}$ & $(\rho \beta)_{h n f}=\left\{\left(1-\phi_{A_{2} O_{3}}\right)\left[1-\phi_{C u}\right](\rho \beta)_{n f}+\phi_{C u}(\rho \beta)_{C u}\right\}+\phi_{A l_{2} O_{3}}(\rho \beta)_{A l_{2} O_{3}}$ \\
\hline$\left(\rho C_{p}\right)_{n f}=\left(1-\phi_{C u}\right)\left(\rho C_{p}\right)_{f}+\phi_{C u}\left(\rho C_{p}\right)_{C u}$ & $\left\{\begin{array}{c}\rho_{h n f}= \\
\left(1-\phi_{A l_{2} \mathrm{O}_{3}}\right)\left[1-\phi_{C u}\right]\left(\rho C_{p}\right)_{n f}+\left(1-\phi_{C u}\right)\left(\rho C_{p}\right)_{n f} \\
+\phi_{C u}\left(\rho C_{p}\right)_{n f}+\phi_{C u}\left(\rho C_{p}\right)_{C u}\end{array}\right\}+\phi_{A l_{2} \mathrm{O}_{3}}\left(\rho C_{p}\right)_{A l_{2} \mathrm{O}_{3}}$ \\
\hline$\mu_{n f}=\frac{\mu_{f}}{\left(1-\phi_{1}\right)^{2.5}}$ & $\mu_{n f}=\frac{\mu_{n f}}{\left(1-\phi_{1}\right)^{2.5}\left(1-\phi_{2}\right)^{2.5}}$ \\
\hline$\frac{k_{n f}}{k_{f}}=\frac{k_{C u}+(n-1) k_{f}-(n-1) \phi_{c u}\left(k_{f}-k_{s}\right)}{k_{C u}+(n-1) k_{f}+\phi_{c u}\left(k_{f}-k_{s}\right)}$ & $\begin{array}{c}\frac{k_{h n f}}{k_{n f}}=\frac{k_{A l_{2} \mathrm{O}_{3}}+(n-1) k_{n f}-(n-1) \phi_{A l_{2} \mathrm{O}_{3}}\left(k_{n f}-k_{A l_{2} \mathrm{O}_{3}}\right)}{k_{A l_{2} \mathrm{O}_{3}}+(n-1) k_{n f}+\phi_{A l_{2} \mathrm{O}_{3}}\left(k_{n f}-k_{A l_{2} \mathrm{O}_{3}}\right)} \\
\text { where } \\
\frac{k_{n f}}{k_{f}}=\frac{k_{C u}+(n-1) k_{f}-(n-1) \phi_{C u}\left(k_{f}-k_{C u}\right)}{k_{C u}+(n-1) k_{f}+\phi_{C u}\left(k_{f}-k_{C u}\right)}\end{array}$ \\
\hline
\end{tabular}

Table 2. Nanocomposites and base fluid thermo-physical characteristics.

\begin{tabular}{cccc}
\hline Property & $\mathrm{H}_{\mathbf{2}} \mathrm{O}$ & $\mathrm{Al}_{\mathbf{2}} \mathrm{O}_{3}$ & $\mathrm{Cu}$ \\
\hline$\rho\left(\mathrm{Kg} \mathrm{m}^{-3}\right)$ & 997.1 & 3970 & 8933 \\
$c_{p}\left(\mathrm{Kg}^{-1} \mathrm{~K}^{-1}\right)$ & 4179 & 765 & 385 \\
$k\left(\mathrm{Wm}^{-1} \mathrm{~K}^{-1}\right)$ & 0.6071 & 40 & 400 \\
$\beta \times 10^{-5}\left(\mathrm{~K}^{-1}\right)$ & 21 & 1.67 & 0.85 \\
\hline
\end{tabular}

Introduction of the relevant dimensionless parameters.

$$
\begin{gathered}
u=f^{\prime}(\eta) \frac{b x}{(1-\alpha t)}, v=-f(\eta) \sqrt{\frac{b v_{f}}{(1-\alpha t)}},\left(T_{w}-T_{\infty}\right) \Theta(\eta)=T-T_{\infty}, \eta=y \sqrt{\frac{b}{v_{f}(1-\alpha t)}}, \\
f^{\prime \prime \prime}+\frac{\rho_{h n f}}{\rho_{f}} \frac{\mu_{f}}{\mu_{h n f}}\left[f f^{\prime \prime}-(1+F r)\left(f^{\prime}\right)^{2}-S\left(f^{\prime}+\frac{\eta}{2} f^{\prime \prime}\right)\right] \pm \frac{\mu_{f}}{\mu_{h n f}}\left[G r \Theta+\left(G r^{*} \Theta\right)^{2}\right] \operatorname{Cos} \theta-K r f^{\prime}=0, \\
\left(\frac{k_{h n f}}{k_{f}}+R d\right) \Theta^{\prime \prime}+\operatorname{Pr} \frac{(\rho C p)_{h n f}}{(\rho C p)_{f}}\left(f \Theta^{\prime}-S\left(\Theta+\frac{\eta}{2} \Theta^{\prime}\right)\right)+\frac{\mu_{h n f}}{\mu_{f}} E c \operatorname{Pr}\left(f^{\prime \prime}\right)^{2}+Q \operatorname{Pr} \Theta=0, \\
f(0)=0, \quad f^{\prime}(0)=1+\gamma\left(\frac{\mu_{h n f}}{\mu_{f}}\right) f^{\prime \prime}(0), \quad \Theta^{\prime}(0)=-B_{i}(1-\Theta(0)), \\
F(\infty)=0, \quad \Theta(\infty)=0 .
\end{gathered}
$$




$$
\begin{aligned}
& F r=\frac{C_{b}}{K^{\frac{1}{2}}} x, G r=\frac{g \beta_{f}\left(T_{w}-T_{\infty}\right)}{b u_{w}}, G r^{*}=\frac{g \beta_{f}^{2}\left(T_{w}-T_{\infty}\right)^{2}}{b u_{w}}, \gamma=\sqrt{\frac{b}{v_{f}(1-\alpha t)}}, R d=\frac{16}{3} \frac{\sigma^{*} T_{\infty}^{3}}{k^{*} k}, \\
& B_{i}=\frac{h_{f}}{k_{0}} \sqrt{\frac{v_{f}(1-\alpha t)}{b}}, K r=\frac{v_{f}}{b k}, E c=\frac{u_{w}^{2}}{c_{p}\left(T_{w}-T_{\infty}\right)}, \operatorname{Pr}=\frac{v_{f}\left(\rho c_{p}\right)}{k_{f}}, Q=\frac{Q_{0}}{b\left(\rho c_{p}\right)_{f}}, S=\frac{\alpha}{b} .
\end{aligned}
$$

Dimensionless expressions can be formed using the parameters mentioned above in Equation (5).

Interrelated constraints on the boundary are:

Where the above-resulting expressions represent the Darcy-Forchheimer parameter, the Grashof numbers in terms of linear and nonlinear convection, the slip parameter, the radiation variable, the Biot number, the Porosity parameter, the Eckert, Prandtl numbers, heat generation parameter, and unsteadiness parameter.

Additionally, the skin friction coefficients $\left(C_{f x}\right)$, as well as the Nusselt number $\left(N u_{x}\right)$, are of relevance from a physical perspective:

$$
C_{f}=\frac{\tau_{w}}{\frac{1}{2} \rho_{h n f}\left(u_{w}\right)^{2}}, \quad N u=\frac{x q_{w}}{k_{h n f}\left(T_{w}-T_{\infty}\right)} .
$$

In Equation (10), $\tau_{w}$ signify the shear stress, where $q_{w}$ denote the heat flux close to the sheet surface. Employing Equation (5), the above Equation (10) becomes:

$$
C_{f} R e^{0.5}=\frac{2}{\left(1-\phi_{1}\right)^{2.5}\left(1-\phi_{2}\right)^{2.5}} \cdot f^{\prime \prime}(0), \quad N u R e^{-0.5}=-\left(\frac{k_{h n f}}{k_{f}}+R d\right) \Theta^{\prime}(0) .
$$

\section{Method of Solution}

In this section, the homotopy analysis method (HAM) is applied to solve Equations (6) and (7) with the help of the physical conditions given in Equation (8). This method was first introduced by Liao [39] for the solution of nonlinear problems. The recent advancement has been made by the authors [40-42] to make this method more effective. Mathematica software is utilized for this purpose. The following description provides a basic explanation of the model equation using the HAM method.

$$
\begin{gathered}
\widehat{F}(\eta)=-\left[\frac{\gamma}{(1+\gamma)}\right] \frac{\mu_{h n f}}{\mu_{f}} e^{-\eta}, \quad \widehat{\Theta}(\eta)=\frac{B_{i}}{\left(1+B_{i}\right)} e^{-\eta}, \\
L_{\widehat{F}}(\widehat{F})=\widehat{f}^{\prime \prime \prime}, \mathrm{L}_{\widehat{\Theta}}(\widehat{\Theta})=\widehat{\Theta}^{\prime \prime} .
\end{gathered}
$$

Linear operators $L_{\widehat{F}}$, and $\mathrm{L}_{\widehat{\Theta}}$ are signified as

$$
L_{\widehat{F}}\left(c_{1}+c_{2} \eta+c_{3} \eta^{2}\right)=0, \quad \mathrm{~L}_{\widehat{\Theta}}\left(c_{4}+c_{5} \eta\right)=0
$$

We recognize the non-linear variables that are commonly referred to as $N_{\widehat{F}}$, and $N_{\widehat{\Theta}}$ in the scheme:

$$
\begin{aligned}
& N_{\widehat{F}}[\widehat{F}(\eta ; \zeta)]=\widehat{F}_{\eta \eta \eta}+\frac{\rho_{h n f}}{\rho_{f}} \frac{\mu_{f}}{\mu_{h n f}}\left[\widehat{F} \widehat{F}_{\eta \eta}-(1+F r) \widehat{F}_{\eta \eta}^{2}-S\left(\widehat{F}_{\eta}+\frac{\eta}{2} \widehat{F}_{\eta \eta}\right)\right] \\
& \pm \frac{\mu_{f}}{\mu_{h n f}}\left[G r \widehat{\Theta}+(G r \widehat{\Theta})^{2}\right] \operatorname{Cos} \theta-K \widehat{F}_{\eta} \\
& N_{\widehat{\Theta}}[\widehat{F}(\eta ; \zeta), \widehat{\Theta}(\eta ; \zeta)]=\left(\frac{k_{h n f}}{k_{f}}+R d\right) \widehat{\Theta}_{\eta \eta}+\operatorname{Pr} \frac{(\rho C p)_{h n f}}{(\rho C p)_{f}}\left[\widehat{F} \widehat{\Theta}_{\eta}-S\left(\widehat{\Theta}+\frac{\eta}{2} \widehat{\Theta}_{\eta}\right)\right]
\end{aligned}
$$

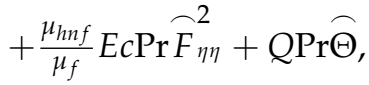


By utilizing the above expression zero-order set of the problem is:

$$
\begin{aligned}
& (1-\zeta) L_{\widehat{F}}\left[\widehat{F}(\eta ; \zeta)-\widehat{F}_{0}(\eta)\right]=p \hbar_{\widehat{F}} N_{\widehat{F}}[\widehat{F}(\eta ; \zeta)], \\
& (1-\zeta) L_{\widehat{\Theta}}\left[\widehat{\Theta}(\eta ; \zeta)-\widehat{\Theta}_{0}(\eta)\right]=p \hbar_{\widehat{\Theta}} N_{\widehat{\Theta}}[F(\eta ; \zeta), \widehat{\Theta}(\eta ; \zeta)],
\end{aligned}
$$

Whereas BCs are:

$$
\begin{aligned}
& \left.\widehat{F}(\eta ; \zeta)\right|_{\eta=0}=0,\left.\quad \frac{\partial \widehat{F}(\eta ; \zeta)}{\partial \eta}\right|_{\eta=0}=1+\frac{\mu_{h n f}}{\mu_{f}} \gamma f^{\prime \prime}(0), \\
& \left.\widehat{F}(\eta ; \zeta)\right|_{\eta=\infty} \rightarrow 0,\left.\quad \frac{\partial \widehat{\Theta}(\eta ; \zeta)}{\partial \eta}\right|_{\eta=0}=-B_{i}(1-\Theta(0)), \\
& \left.\widehat{\Theta}(\eta ; \zeta)\right|_{\eta=\infty} \rightarrow 0 .
\end{aligned}
$$

where the embedding constraint is $\zeta \in[0,1]$, to manipulate for congruence of solutions assumed $\hbar_{\widehat{F}}$, $\hbar_{\widehat{\Theta}}$ and $\hbar_{\widehat{\Phi}}$. At the value of $\zeta=0$ and $\zeta=1$, we have:

$$
\widehat{F}(\eta ; 1)=\widehat{F}(\eta), \quad \widehat{\Theta}(\eta ; 1)=\widehat{\Theta}(\eta) .
$$

Considering Taylor's series, the expansion of $\widehat{F}(\eta ; \zeta)$ and $\widehat{\Theta}(\eta ; \zeta)$ at $\zeta=0$ is

$$
\begin{gathered}
\widehat{F}(\eta ; \zeta)=\widehat{F}_{0}(\eta)+\sum_{n=1}^{\infty} \widehat{F}_{n}(\eta) \zeta^{n}, \\
\widehat{\Theta}(\eta ; \zeta)=\widehat{\Theta}_{0}(\eta)+\sum_{n=1}^{\infty} \widehat{\Theta}_{n}(\eta) \zeta^{n} . \\
\widehat{F}_{n}(\eta)=\left.\frac{1}{n !} \cdot \frac{\partial(\eta ; \zeta)}{\partial \eta}\right|_{p=0}, \quad \widehat{\Theta}_{n}(\eta)=\left.\frac{1}{n !} \cdot \frac{\partial \Phi(\eta ; \zeta)}{\partial \eta}\right|_{p=0} .
\end{gathered}
$$

While boundary conditions are:

$$
\begin{aligned}
& f(0)=0, f^{\prime}(0)=1+\frac{\mu_{h n f}}{\mu_{f}} \gamma f^{\prime \prime}(0), \\
& F(\infty)=0, \Theta^{\prime}(0)=-B_{i}(1-\Theta(0)), \\
& \Theta(\infty)=0 .
\end{aligned}
$$

Now

$$
\begin{aligned}
& \Re_{n}^{\widehat{F}}(\eta)=\widehat{F}_{n-1}^{\prime \prime \prime}+\frac{\rho_{h n f}}{\rho_{f}} \frac{\mu_{f}}{\mu_{h n f}}\left[\sum_{j=0}^{w-1} \widehat{F}_{w-1-j} \widehat{F}_{j}^{\prime \prime}-(1+F r){\widehat{F^{\prime}}}_{n-1}^{2}-S\left(\widehat{F}_{n-1}+\frac{\eta}{2} \widehat{F}_{n-1}\right)\right] \\
& \pm \frac{\mu_{f}}{\mu_{h n f}}\left[G r \widehat{\Theta}_{n-1}-\left(G r \widehat{\Theta}_{n-1}\right)^{2}\right] \operatorname{Cos} \theta-K F_{n-1}^{\prime}=0 \text {, } \\
& \Re_{n}^{\widehat{\Theta}}(\eta)=\left(\frac{k_{h n f}}{k_{f}}+1\right) \widehat{\Theta}_{n-1}^{\prime \prime}+\operatorname{Pr} \frac{(\rho C p)_{h n f}}{(\rho C p)_{f}}\left(\sum_{j=0}^{w-1} \widehat{F}_{w-1-j} \widehat{\Theta}_{j}^{\prime}-S\left(\widehat{\Theta}_{j}+\frac{\eta}{2}{\widehat{\Theta^{\prime}}}_{j}\right)\right) \\
& +\frac{\mu_{h n f}}{\mu_{f}} E c \operatorname{Pr}_{F^{\prime \prime}}^{2}{ }_{n-1}^{2}+Q \operatorname{Pr} \widehat{\Theta}_{n-1}=0,
\end{aligned}
$$

Whereas

$$
\chi_{n}=\left\{\begin{array}{l}
0, \text { if } \zeta \leq 1 \\
1, \text { if } \zeta>1
\end{array}\right.
$$




\section{Results and Discussion}

The influence of the various embedded parameters over the velocity and temperature profiles are investigated and displayed. These parameters include the inertia coefficient $\mathrm{Fr}$, the Grashof numbers $\mathrm{Gr}, \mathrm{Gr}^{*}$, the Radiation factor $R d$, the Prandtl number $\mathrm{Pr}$, the Porosity factor $\mathrm{Kr}$, the Eckert number $\mathrm{Ec}$ using the $\mathrm{Cu}+\mathrm{Al}_{2} \mathrm{O}_{3} / \mathrm{H}_{2} \mathrm{O}$ hybrid nanofluid, and $\mathrm{Cu} / \mathrm{H}_{2} \mathrm{O}$ nanofluid. The geometry of the problem is shown in Figure 1 . The total square residual sum of the obtained and displayed in Figure 2. The iterations are obtained up to the 30th order approximation. This shows that with the increasing number of iterations, the convergence rate increases. Figures 3-6 depict the performance of $F^{\prime}(\eta)$ varied values of the developing parameters.

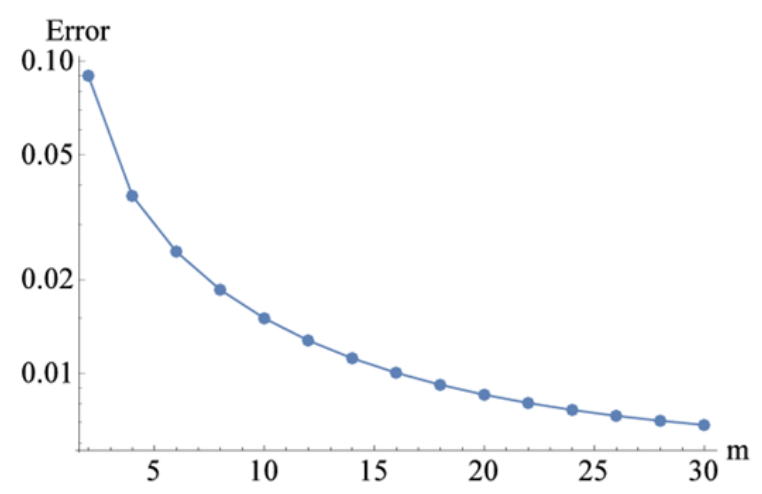

Figure 2. Total square residual sum of the problem.
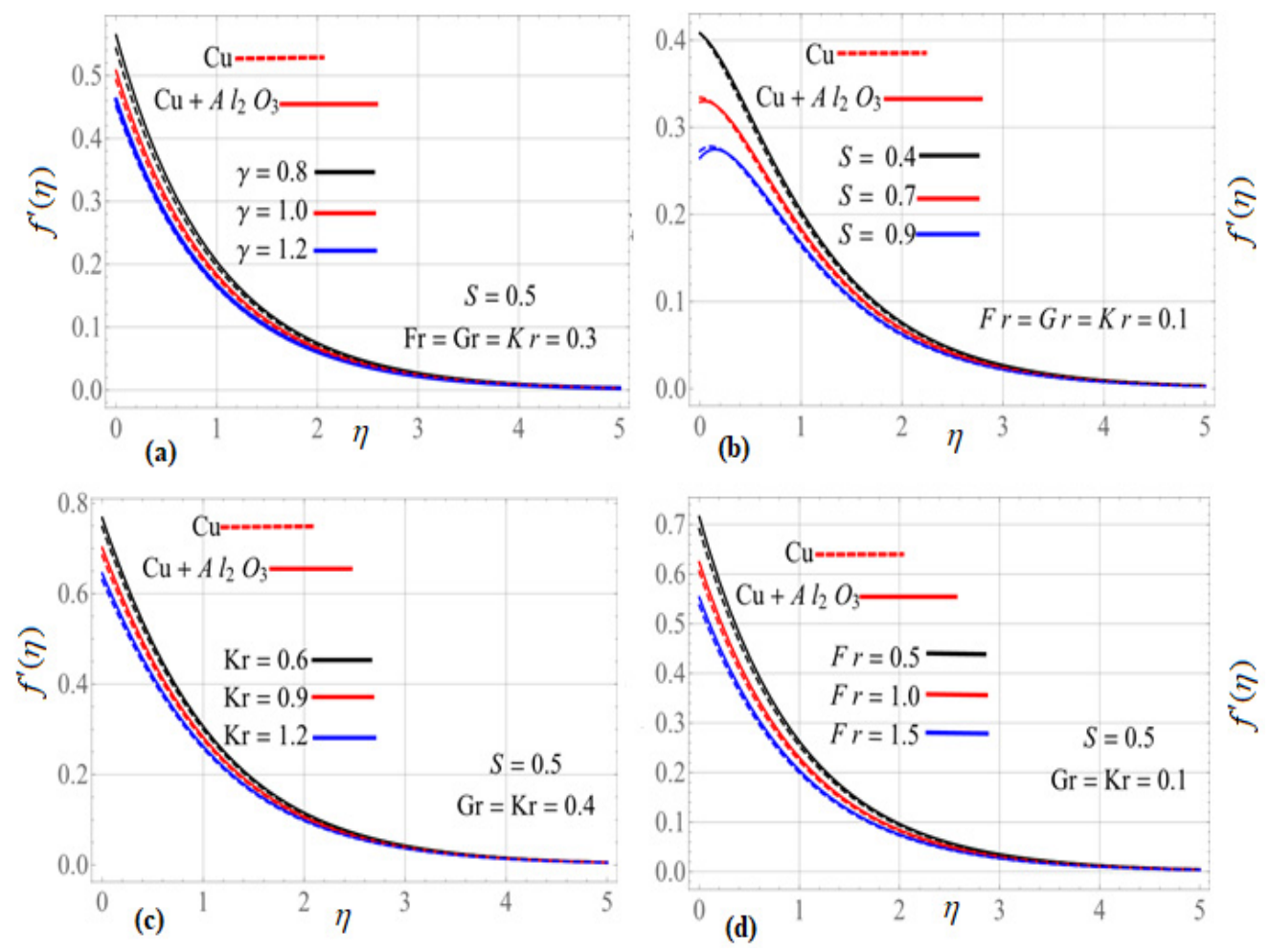

Figure 3. (a-d) Impact of $\gamma, S, K r, F r$ on $F^{\prime}(\eta)$ for $\mathrm{Cu}+\mathrm{Al}_{2} \mathrm{O}_{3} / \mathrm{H}_{2} \mathrm{O}$ versus $\mathrm{Cu} / \mathrm{H}_{2} \mathrm{O}$. 


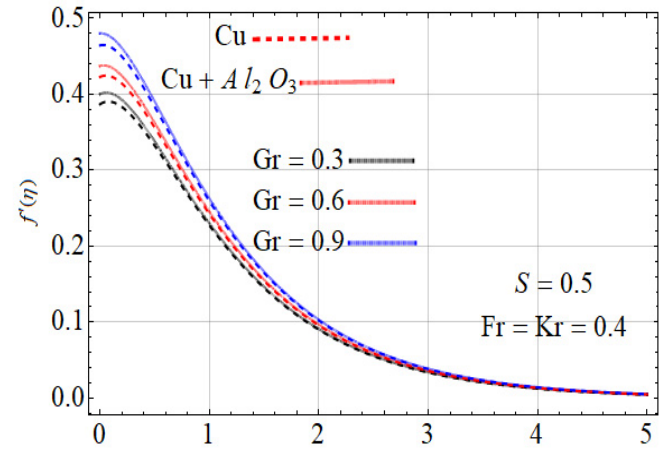

(a)

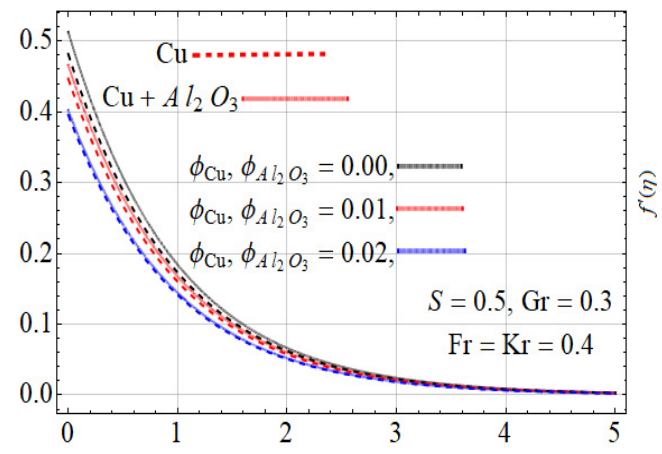

(b)

Figure 4. (a,b) Impact of $\mathrm{Gr}, \phi_{\mathrm{Cu}}, \phi_{\mathrm{Al}_{2} \mathrm{O}_{3}}$ on $\mathrm{F}^{\prime}(\eta)$ for $\mathrm{Cu}+\mathrm{Al}_{2} \mathrm{O}_{3} / \mathrm{H}_{2} \mathrm{O}$ versus $\mathrm{Cu} / \mathrm{H}_{2} \mathrm{O}$.
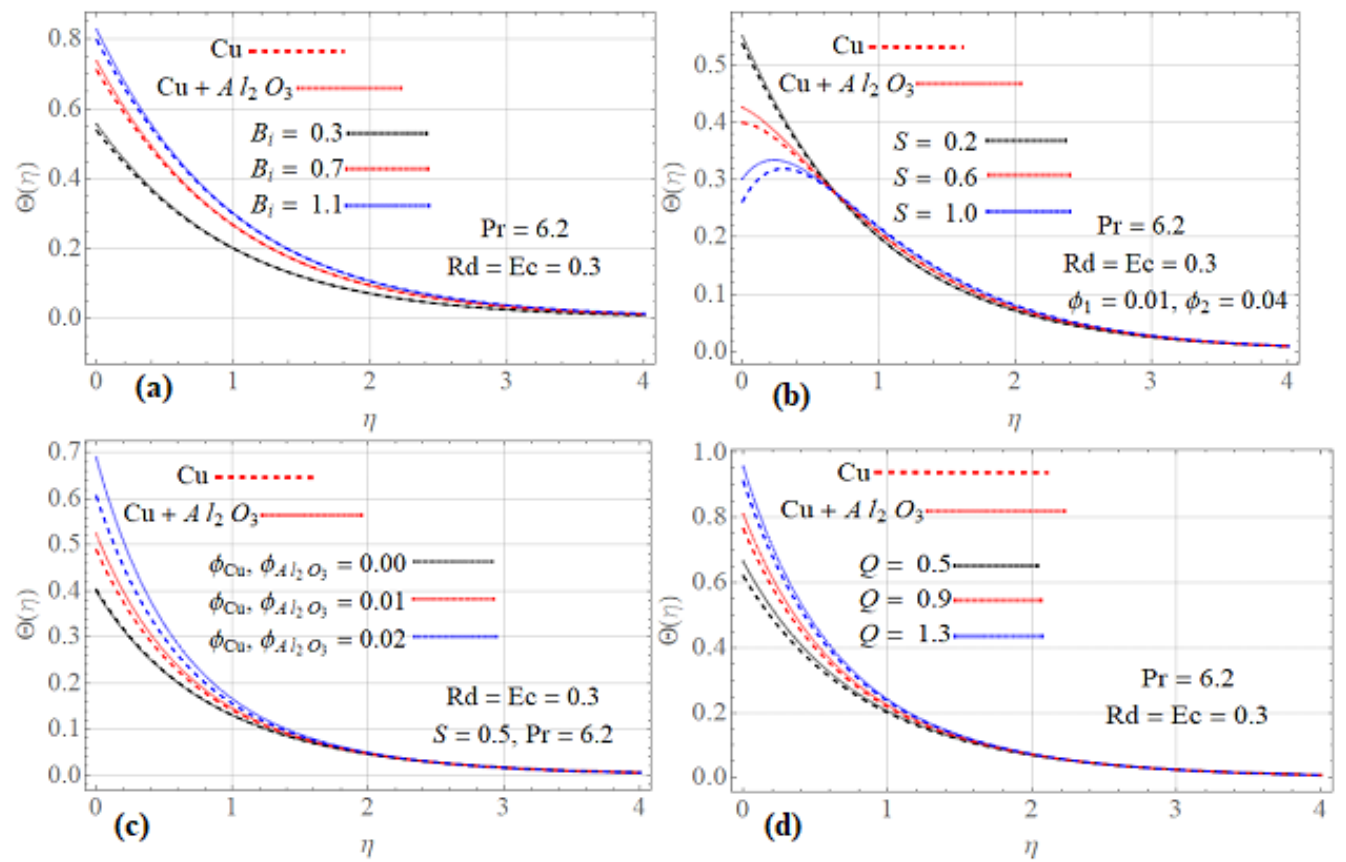

Figure 5. (a-d) Influence of $B_{i}, S, \phi_{C u}, \phi_{\mathrm{Al}_{2} \mathrm{O}_{3}}, Q$ on $\Theta(\eta)$ for $\mathrm{Cu}+\mathrm{Al}_{2} \mathrm{O}_{3} / \mathrm{H}_{2} \mathrm{O}$ versus $\mathrm{Cu} / \mathrm{H}_{2} \mathrm{O}$.

\section{Error Analysis}

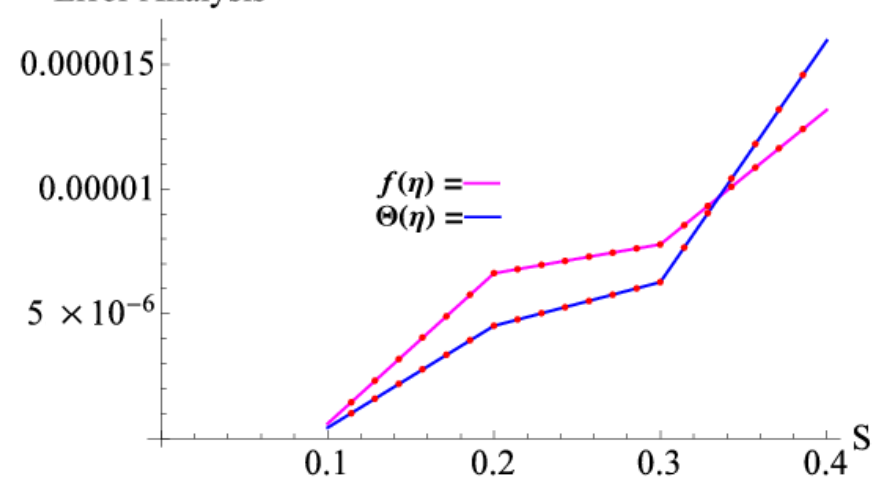

Figure 6. Parameter range of the common unsteady parameter $S$.

The influence of the slide factor $\gamma$ on $F^{\prime}(\eta)$ velocity distribution is illustrated in Figure $3 \mathrm{a}$ for the hybrid nano liquid $\left(\mathrm{Cu}+\mathrm{Al}_{2} \mathrm{O}_{3} / \mathrm{H}_{2} \mathrm{O}\right)$ and the nano liquid $\left(\mathrm{Cu} / \mathrm{H}_{2} \mathrm{O}\right)$. The figures indicate that the velocity profile $F^{\prime}(\eta)$ declines by improving the sliding factor, but on the other hand, the temperature profiles show the opposite tendency. It is because a 
reduction in surface friction between the stretched sheet and liquid occurs as the sliding factor increases. The thickness of the fluid layer also decreases as the slide parameter increases. However, an increase in the sliding parameter generates the frictional force, which allows more liquid to slide past the sheet and the deceleration of the flow, and the temperature field is increased due to the action of force. Moreover, the maximum velocity is observed for hybrid nano liquid $\left(\mathrm{Cu}+\mathrm{Al}_{2} \mathrm{O}_{3} / \mathrm{H}_{2} \mathrm{O}\right)$ compared with the nano liquid $\left(\mathrm{Cu} / \mathrm{H}_{2} \mathrm{O}\right)$.

The consequence of the unsteadiness factor $S$ on the $F^{\prime}(\eta)$ velocity profile for hybrid nanofluids $\left(\mathrm{Cu}+\mathrm{Al}_{2} \mathrm{O}_{3} / \mathrm{H}_{2} \mathrm{O}\right)$ and nanofluids $\left(\mathrm{Cu} / \mathrm{H}_{2} \mathrm{O}\right)$ is shown in Figure $3 \mathrm{~b}$. The velocity profiles are demonstrated to be reduced whenever the unsteadiness factor is increased. Because the width of the momentum boundary is reduced as the unsteadiness parameter is increased, the velocity along with the sheet drops. It is observed that $F^{\prime}(\eta)$ is higher for hybrid nanofluid $\left(\mathrm{Cu}+\mathrm{Al}_{2} \mathrm{O}_{3} / \mathrm{H}_{2} \mathrm{O}\right)$ than nanofluid $\left(\mathrm{Cu} / \mathrm{H}_{2} \mathrm{O}\right)$. Figure $3 \mathrm{c}$ depicts the effect of the porosity parameter $\mathrm{Kr}$. The impact of the $\mathrm{Kr}$ on $F^{\prime}(\eta)$ for hybrid nanofluids $\left(\mathrm{Cu}+\mathrm{Al}_{2} \mathrm{O}_{3} / \mathrm{H}_{2} \mathrm{O}\right)$ and nanofluids $\left(\mathrm{Cu} / \mathrm{H}_{2} \mathrm{O}\right)$ is investigated. An increase in the permeability parameter reduces the fluid motion and this happens due to the resistance force generation due to the porous medium. Similarly, in evaluation, the $F^{\prime}(\eta)$ velocity $\mathrm{Cu}+\mathrm{Al}_{2} \mathrm{O}_{3} / \mathrm{H}_{2} \mathrm{O}$ is shown to be greater than that of $\mathrm{Cu} / \mathrm{H}_{2} \mathrm{O}$.

In Figure 3d, a velocity profile for hybrid nanofluids $\left(\mathrm{Cu}+\mathrm{Al}_{2} \mathrm{O}_{3} / \mathrm{H}_{2} \mathrm{O}\right)$ and nanofluids $\left(\mathrm{Cu} / \mathrm{H}_{2} \mathrm{O}\right)$ is compared for various values of $\mathrm{Fr}$ (inertia coefficient parameter). The velocity profile shows a decreasing influence as the amount of the object increases in the graph $\mathrm{Fr}$ (Inertia coefficient factor). Inertia is a mass's physical ability to resist transition, allowing it to move more powerfully; as a result, it reduces fluid motion. It is also found that the velocity of fluid $F^{\prime}(\eta)$ of $\mathrm{Cu} / \mathrm{H}_{2} \mathrm{O}$ nanofluids is lower than that of $\mathrm{Cu}+\mathrm{Al}_{2} \mathrm{O}_{3} / \mathrm{H}_{2} \mathrm{O}$. The Grashof numbers $(\mathrm{Gr})$ influence on the velocity profile consisting of hybrid nanofluids $\left(\mathrm{Cu}+\mathrm{Al}_{2} \mathrm{O}_{3} / \mathrm{H}_{2} \mathrm{O}\right)$ and nanofluids $\left(\mathrm{Cu} / \mathrm{H}_{2} \mathrm{O}\right)$ are displayed in Figure 4a. This graph shows that when the value rises, the fluid velocity rises as well. This is because $\mathrm{Gr}$ (the thermal Grashof number) includes both thermal and hydrodynamic buoyancy forces and arises on the boundary layer as a result of temperature changes. In addition, the inset plot reveals that $\mathrm{Cu} / \mathrm{H}_{2} \mathrm{O}$ the nanofluid velocity field $\mathrm{F}^{\prime}(\eta)$ is often lower than the $\left(\mathrm{Cu}+\mathrm{Al}_{2} \mathrm{O}_{3} / \mathrm{H}_{2} \mathrm{O}\right)$ hybrid nanofluid. The flow field of both hybrid nanofluid $\left(\mathrm{Cu}+\mathrm{Al}_{2} \mathrm{O}_{3} / \mathrm{H}_{2} \mathrm{O}\right)$ and $\left(\mathrm{Cu} / \mathrm{H}_{2} \mathrm{O}\right)$ nanofluids is influenced by nanoparticle concentration $\phi_{\mathrm{Cu}}, \phi_{\mathrm{Al}_{2} \mathrm{O}_{3}}$, as seen in Figure $4 \mathrm{~b}$. As the volume fraction increases, the proportion of nanoparticles increases, and as a result, the velocity and flow boundary layer reduces. Nanofluid $\left(\mathrm{Cu} / \mathrm{H}_{2} \mathrm{O}\right)$ flow slower than the $\left(\mathrm{Cu}+\mathrm{Al}_{2} \mathrm{O}_{3} / \mathrm{H}_{2} \mathrm{O}\right)$ hybrid nanofluid for volume fraction increment, it is because $\mathrm{Cu} / \mathrm{H}_{2} \mathrm{O}$ is denser than $\mathrm{Cu}+\mathrm{Al}_{2} \mathrm{O}_{3} / \mathrm{H}_{2} \mathrm{O}$. The Biot number $\mathrm{B}_{i}$ is a dimensionless measure of the relative transit of external and interior resistances. The hot fluids heat the lower surface of an extending surface as the temperature of the sheet rises, resulting in convective heat transfer. As a result, the thermal boundary layer is enhanced, as displayed in Figure $5 \mathrm{a}$ for hybrid nanofluid $\left(\mathrm{Cu}+\mathrm{Al}_{2} \mathrm{O}_{3} / \mathrm{H}_{2} \mathrm{O}\right)$ and nanofluid $\left(\mathrm{Cu} / \mathrm{H}_{2} \mathrm{O}\right)$, respectively. Because the coefficient of heat transfer is in direct relation to $B_{i}$, the non-dimensional heat transfer rate for the hybrid nanofluid increases dramatically when compared with nanofluid.

Figure $5 \mathrm{~b}$ illustrates that the $\Theta(\eta)$ temperature distribution for hybrid nano liquid $\left(\mathrm{Cu}+\mathrm{Al}_{2} \mathrm{O}_{3} / \mathrm{H}_{2} \mathrm{O}\right)$ is stronger compared with common nano liquid $\left(\mathrm{Cu} / \mathrm{H}_{2} \mathrm{O}\right)$. In this figure, the temperature profile increases with the positive incrementation in the value of $S$.

As shown in Figure $5 c$, the $\Theta(\eta)$ temperature profile of nanoscale volume fractions is influenced by a variety of factors $\phi_{\mathrm{C} u}, \phi_{\mathrm{Al}_{2} \mathrm{O}_{3}}$. With increasing particle concentrations $\phi_{\mathrm{Cu}}, \phi_{\mathrm{Al}_{2} \mathrm{O}_{3}}$, this figure shows a significant rise in the temperature profile $\Theta(\eta)$. The cause for this is that adding varying volume fractions of nanoparticles $\phi_{C u}, \phi_{\mathrm{Al}_{2} \mathrm{O}_{3}}$ changes the heat features of the hosting fluid, which raises the temperature $\Theta(\eta)$. The hybrid nanofluid $\left(\mathrm{Cu}+\mathrm{Al}_{2} \mathrm{O}_{3} / \mathrm{H}_{2} \mathrm{O}\right)$ demonstrates its domination over nanofluid $\left(\mathrm{Cu} / \mathrm{H}_{2} \mathrm{O}\right)$ in this graph.

Figure $5 \mathrm{~d}$ depicts the outlines of the $\mathrm{Cu}+\mathrm{Al}_{2} \mathrm{O}_{3} / \mathrm{H}_{2} \mathrm{O}$ (hybrid nanofluid) and $\mathrm{Cu} / \mathrm{H}_{2} \mathrm{O}$ (nanofluid) versus thermal fields $\Theta(\eta)$ as a function of various values of $Q$. The $\Theta(\eta)$ is enhanced when the value of $Q$ (heat source/sink) increases, as shown in Figure 5d. On 
the other hand, $Q$ the component that occurs in the heat expression defines the measure of heat production per unit volume given by $Q\left(T-T_{1}\right)$, although $Q$ can be interpreted favourably or negatively. The source formulation represents a value of $Q>0$ (absorption of the heat) and a value of $Q<0$ (heat generation). A larger amount of $Q$ significantly raises the temperature of the fluid, as seen in the graph. Heat sources/sinks can also be employed in the materials storage device. When the surrounding fluid and surface have a large temperature difference, the heat source/sink is active, allowing heat transfer to be managed.

The range of parameters has been displayed in Figure 6. The range of the parameters are obtained based on the convergence of the HAM technique. The unsteady parameter is a common parameter in both momentum and thermal boundary layers. Therefore, the convergence of the method is mainly focused on the common parameters. In addition, Table 2 predicts the thermo-physical features of nanoparticles and base fluids. The physical effect of $\gamma, S, K r, F r$, and $G r, G r^{*}$ on $C_{f}$ for $\mathrm{Cu} / \mathrm{H}_{2} \mathrm{O}$ nanofluid is estimated in Table 3. However, whereas $S, K r$, and $F r$ appear to enhance skin friction coefficients, for $\gamma$ and $\mathrm{Gr}$ this has the opposite effect. Table 4 shows the influence of operational factors such as $B_{i}, S, E c, R d, G r$, and $Q$ on the $\mathrm{Nu}$ heat transfer rate for $\mathrm{Cu} / \mathrm{H}_{2} \mathrm{O}$ nanofluid.

Table 3. The combination of quantitative data versus a set of variables.

\begin{tabular}{|c|c|c|c|c|c|c|c|}
\hline$\gamma$ & $S$ & $K r$ & $F r$ & $G r$ & $G r^{*}$ & $\begin{array}{c}C_{f x} R e_{x}{ }^{0.5} \\
C u\end{array}$ & $\begin{array}{c}C_{f x} \operatorname{Re}_{x}{ }^{0.5} \\
C u+A l_{2} O_{3}\end{array}$ \\
\hline 0.1 & 0.1 & 0.1 & 0.1 & 0.1 & 0.1 & 1.02363 & 1.0237 \\
\hline 0.2 & & & & & & 0.938348 & 0.938522 \\
\hline \multirow[t]{16}{*}{0.3} & & & & & & 0.866086 & 0.866346 \\
\hline & 0.1 & & & & & 1.02363 & 1.0237 \\
\hline & 0.2 & & & & & 1.0301 & 1.03477 \\
\hline & 0.3 & & & & & 1.03681 & 1.04096 \\
\hline & & 0.1 & & & & 1.02363 & 1.0237 \\
\hline & & 0.2 & & & & 1.03567 & 1.03569 \\
\hline & & 0.3 & & & & 1.03845 & 1.04041 \\
\hline & & & 0.1 & & & 1.02363 & 1.0237 \\
\hline & & & 0.2 & & & 1.04186 & 1.04622 \\
\hline & & & 0.3 & & & 1.05064 & 1.05453 \\
\hline & & & & 0.1 & & 1.02363 & 1.0237 \\
\hline & & & & 0.2 & & 1.01474 & 1.01592 \\
\hline & & & & 0.3 & & 1.0053 & 1.00765 \\
\hline & & & & & 0.1 & 1.02363 & 1.0237 \\
\hline & & & & & 0.2 & 1.020214 & 1.02013 \\
\hline & & & & & 0.3 & 1.016310 & 1.016281 \\
\hline
\end{tabular}

Table 4. The combination of quantitative data versus a set of variables.

\begin{tabular}{|c|c|c|c|c|c|c|c|}
\hline$B_{i}$ & $S$ & $E c$ & $R d$ & $G r$ & $Q$ & $\begin{array}{c}N u_{x} R e_{x}^{-0.5} \\
C u\end{array}$ & $\begin{array}{c}N u_{x} \mathrm{Re}_{x}-0.5 \\
\mathrm{Cu}+\mathrm{Al}_{2} \mathrm{O}_{3}\end{array}$ \\
\hline 1 & 0.1 & 0.1 & 0.1 & 0.1 & 0.5 & 1.013145 & 1.05777 \\
\hline 1.1 & & & & & & 1.15634 & 1.16634 \\
\hline \multirow[t]{16}{*}{1.2} & & & & & & 1.18005 & 1.21031 \\
\hline & 0.1 & & & & & 1.013145 & 1.05777 \\
\hline & 0.2 & & & & & 1.00395 & 1.01158 \\
\hline & 0.3 & & & & & 0.902247 & 0.965545 \\
\hline & & 0.1 & & & & 1.013145 & 1.05777 \\
\hline & & 0.2 & & & & 1.12721 & 1.1701 \\
\hline & & 0.3 & & & & 1.19808 & 1.23711 \\
\hline & & & 0.1 & & & 1.013145 & 1.05777 \\
\hline & & & 0.2 & & & 1.07488 & 1.09531 \\
\hline & & & 0.3 & & & 1.08934 & 1.10979 \\
\hline & & & & 0.1 & & 1.013145 & 1.05777 \\
\hline & & & & 0.2 & & 1.17754 & 1.19043 \\
\hline & & & & 0.3 & & 1.21896 & 1.25974 \\
\hline & & & & & 0.1 & 1.013145 & 1.05777 \\
\hline & & & & & 0.2 & 1.19876 & 1.21804 \\
\hline & & & & & 0.3 & 1.26676 & 1.29415 \\
\hline
\end{tabular}


In Table 5, the enhancement in heat transfer rate for the hybrid nanofluid $(\mathrm{Cu}+$ $\left.\mathrm{Al}_{2} \mathrm{O}_{3} / \mathrm{H}_{2} \mathrm{O}\right)$ and nanofluids $\left(\mathrm{Cu} / \mathrm{H}_{2} \mathrm{O}\right)$ have been calculated in percentage and the effect of $\phi_{\mathrm{Cu}}, \phi_{\mathrm{Al}_{2} \mathrm{O}_{3}}$ against $\mathrm{Nu}_{x} \mathrm{Re}_{x}{ }^{-0.5}$. Figure 7 explains the \% wise statistical data for each one parameter versus heat transfer rate, whereas Figure 8 is picketed for $\phi_{\mathrm{Cu}}, \phi_{\mathrm{Al}_{2} \mathrm{O}_{3}}$ versus $N u_{x} R e_{x}{ }^{-0.5}$. In light of the obtained results, it has been observed that hybrid nanofluid is more efficient for augmentation of heat transfer rate in comparison with nanofluid.

Table 6 compares the current outcomes to those of Wang (Golra and Sidawi) $[43,44]$ in order to explain the best agreement. It is observed that there is a clear consensus amongst the current findings and those in Refs. [43,44].

Table 5. For each nanoparticle, the heat transmission has been determined in percent $\operatorname{Pr}=6.2, S=0.1, E c=0.3$, by applying the percentage $\%$ formula Percentage Increase $=\frac{\text { With Nano-particle }}{\text { Without Nano-particle }} \times 100=$ Result,

Result $-100=$ Percentage enhancment.

\begin{tabular}{|c|c|c|}
\hline$\phi_{\mathrm{Cu}}, \phi_{\mathrm{Al}_{2} \mathrm{O}_{3}}$ & $\begin{array}{c}\Theta^{\prime}(0) \\
\text { Nanofluid } \\
C u\end{array}$ & $\begin{array}{c}\Theta^{\prime}(0) \\
\text { Hybrid Nanofluid } \\
C u+A l_{2} O_{3}\end{array}$ \\
\hline 0.0 & $\begin{array}{c}2.06469 \\
(0 \% \text { Increase) }\end{array}$ & $\begin{array}{c}2.06469 \\
(0 \% \text { Increase })\end{array}$ \\
\hline 0.01 & $\begin{array}{c}2.09138 \\
(1.29 \% \text { Increase) }\end{array}$ & $\begin{array}{c}2.09857 \\
(1.64 \% \text { Increase) }\end{array}$ \\
\hline 0.02 & $\begin{array}{c}2.11871 \\
(2.62 \% \text { Increase) }\end{array}$ & $\begin{array}{c}2.13360 \\
(3.34 \% \text { Increase) }\end{array}$ \\
\hline 0.03 & $\begin{array}{c}2.14671 \\
(3.97 \% \text { Increase) }\end{array}$ & $\begin{array}{c}2.16984 \\
(5.09 \% \text { Increase) }\end{array}$ \\
\hline
\end{tabular}

\section{Heat Transfer Rate Percentage Wise}

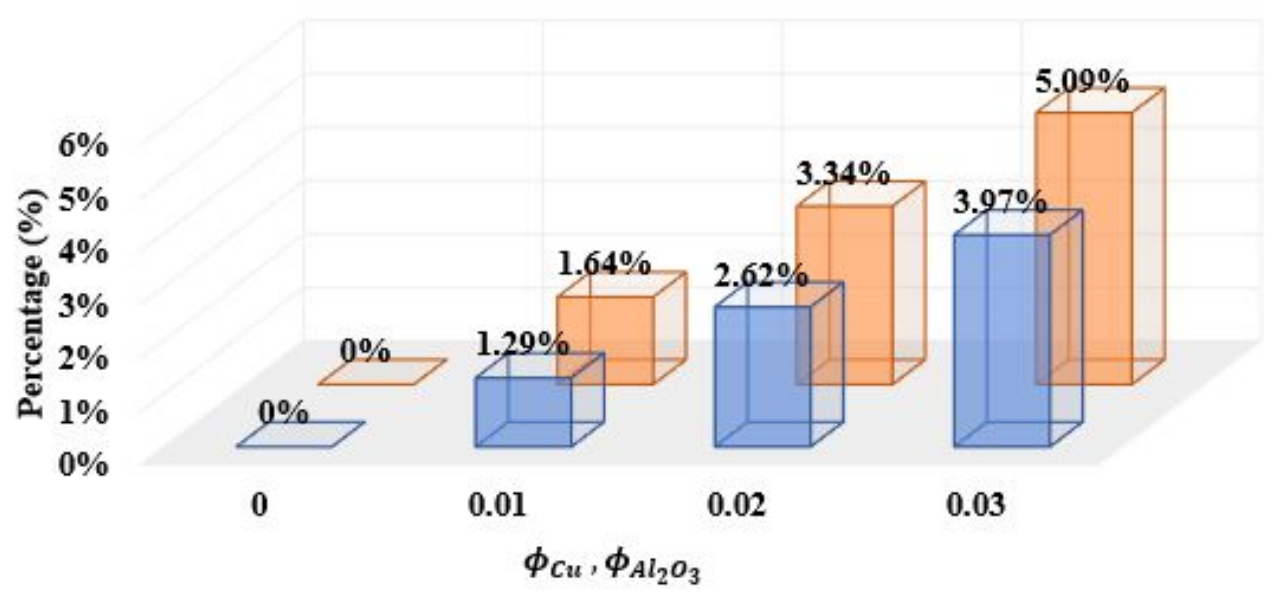

Figure 7. Percentage versus $\phi_{\mathrm{Cu}}, \phi_{\mathrm{Al}_{2} \mathrm{O}_{3}}$. 


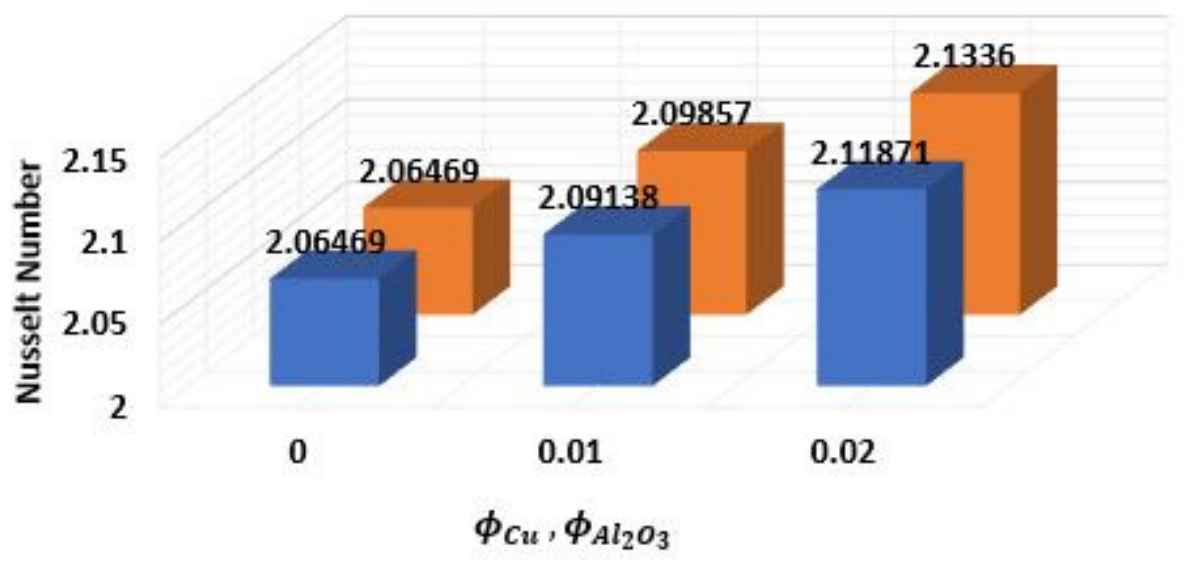

\section{Nanofluid Hybrid Nanofluid}

Figure 8. Versus $\phi_{\mathrm{Cu}}, \phi_{\mathrm{Al}_{2} \mathrm{O}_{3}}$.

Table 6. Comparison with $[43,44]$ taking $N u_{x} R e_{x}{ }^{-0.5}$.

\begin{tabular}{cccc}
\hline Pr & Ref. [43] & Ref. [44] & Present \\
\hline 6.2 & 1.54276 & 1.54288 & 1.54289 \\
6.4 & 1.52165 & 1.52176 & 1.52178 \\
6.6 & 1.50043 & 1.50054 & 1.50057 \\
\hline
\end{tabular}

\section{Conclusions}

Physical characteristics of the hybrid nanofluid flow over an inclined surface are investigated in this study. $\mathrm{H}_{2} \mathrm{O}$ (Water) is utilized as a base liquid in a hybrid nanofluid containing nanoparticles. The current study has looked at the Darcy-Forchheimer model, solar radiation, heat source, and viscous dissipation. The fundamental physical characteristics of the heat transfer rate and solar radiation influences are determined. The uses of these characteristics are related to the same solar panel design. The main outputs are obtained as:

- The velocity of the $\mathrm{Cu} / \mathrm{H}_{2} \mathrm{O}$ and $\mathrm{Cu}+\mathrm{Al}_{3} \mathrm{O}_{3} / \mathrm{H}_{2} \mathrm{O}$ nanofluids decrease with increasing the slip parameter $\gamma$.

- $\quad$ The temperature profile $\Theta(\eta)$ was assessed using a higher number of $B_{i}$ and $Q$ variables.

- The heat transfer rate accelerates as the scale of the thermal radiation parameter increases, and as a result, the Nusselt number rises.

- The heat transfer rate of hybrid nanofluid $\left(\mathrm{Cu}+\mathrm{Al}_{3} \mathrm{O}_{3} / \mathrm{H}_{2} \mathrm{O}\right)$ seems to be higher than that of nanofluid $\left(\mathrm{Cu} / \mathrm{H}_{2} \mathrm{O}\right)$.

- Although nanofluids are more sticky than ordinary fluids, their boiling point is greater than that of conventional base liquids. It could help to increase the heat transfer capacity of the solar panel.

Author Contributions: Investigation, M.Z.U.; Methodology, F.O.M. All authors have read and agreed to the published version of the manuscript.

Funding: Deanship of Scientific Research (DSR) at King Abdulaziz University, Jeddah, Saudi Arabia, under Grant No. G-212-130-1442.

Institutional Review Board Statement: Not applicable.

Informed Consent Statement: Not applicable.

Data Availability Statement: Not applicable. 
Acknowledgments: This project was funded by the Deanship of Scientific Research (DSR) at King Abdulaziz University, Jeddah, under grant no. G: 212-130-1442. The authors, therefore, acknowledge with thanks DSR for technical and financial support.

Conflicts of Interest: The authors declare that they have no conflict of interest.

\section{References}

1. Choi, U.S. Enhancing thermal conductivity of fluids with nanoparticles. AS-MEFED 1995, 231, 99-103.

2. Izadi, A.; Siavashi, M.; Xiong, Q. Impingement jet hydrogen, air and $\mathrm{Cu}-\mathrm{H}_{2} \mathrm{O}$ nanofluid cooling of a hot surface covered by porous media with non-uniform input jet velocity. Int. J. Hydrogen Energy 2019, 44, 15933-15948. [CrossRef]

3. Khanafer, K.; Vafai, K. A review on the applications of nanofluids in solar energy field. Renew. Energy 2018, 123, 398-406. [CrossRef]

4. Basha, H.T.; Sivaraj, R.; Reddy, A.S.; Chamkha, A. SWCNH/diamond ethylene glycol nanofluid flow over a wedge, plate and stagnation point with induced magnetic field and nonlinear radiation-solar energy application. Eur. Phys. J. Spec. Top. 2019, 228, 2531-2551. [CrossRef]

5. Siavashi, M.; Joibary, S.M.M. Numerical performance analysis of a counter-flow double-pipe heat exchanger with using nanofluid and both sides partly filled with porous media. J. Therm. Anal. Calorim. 2019, 135, 1595-1610. [CrossRef]

6. Zhang, H.; Sun, S.; Wang, X.; Wu, D. Fabrication of microencapsulated phase change materials based on n-octadecane core and silica shell through interfacial polycondensation. Colloids Surf. A Physicochem. Eng. Asp. 2011, 389, 104-117. [CrossRef]

7. Mebarek-Oudina, F. Convective heat transfer of Titania nanofluids of different base fluids in cylindrical annulus with discrete heat source. Heat Transf.-Asian Res. 2019, 48, 135-147. [CrossRef]

8. Li, Z.; Saleem, S.; Shafee, A.; Chamkha, A.J.; Du, S. Analytical investigation of nanoparticle migration in a duct considering thermal radiation. J. Therm. Anal. Calorim. 2019, 135, 1629-1641. [CrossRef]

9. Momin, G.G. Experimental investigation of mixed convection with water- $\mathrm{Al}_{2} \mathrm{O}_{3}$ \& hybrid nanofluid in inclined tube for laminar flow. Int. J. Sci. Technol. Res. 2013, 2, 195-202.

10. Zaim, A.; Aissa, A.; Mebarek-Oudina, F.; Mahanthesh, B.; Lorenzini, G.; Sahnoun, M.; El Ganaoui, M. Galerkin finite element analysis of magneto-hydrodynamic natural convection of $\mathrm{Cu}$-water nanoliquid in a baffled U-shaped enclosure. Propuls. Power Res. 2020, 4, 383-393. [CrossRef]

11. Sheikholeslami, M. Magnetic field influence on $\mathrm{CuO}-\mathrm{H}_{2} \mathrm{O}$ nanofluid convective flow in a permeable cavity considering various shapes for nanoparticles. Int. J. Hydrogen Energy 2017, 42, 19611-19621. [CrossRef]

12. Gul, T.; Nasir, S.; Islam, S.; Shah, Z.; Khan, M.A. Effective Prandtl Number Model Influences on the $\gamma \mathrm{Al}_{2} \mathrm{O}_{3}-\mathrm{H}_{2} \mathrm{O}$ and $\gamma \mathrm{Al}_{2} \mathrm{O}_{3}-$ $\mathrm{C}_{2} \mathrm{H}_{6} \mathrm{O}_{2}$ Nanofluids Spray Along a Stretching Cylinder. Arab. J. Sci. Eng. 2019, 44, 1-22.

13. Hayat, T.; Nadeem, S. Heat transfer enhancement with Ag-CuO/water hybrid nanofluid. Results Phys. 2017, 7, 2317-2324. [CrossRef]

14. Chamkha, A.J.; Miroshnichenko, I.V.; Sheremet, M.A. Numerical analysis of unsteady conjugate natural convection of hybrid waterbased nanofluid in a semicircular cavity. J. Therm. Sci. Eng. Appl. 2017, 9, 041004. [CrossRef]

15. Aziz, A.; Jamshed, W.; Ali, Y.; Shams, M. Heat transfer and entropy analysis of Maxwell hybrid nanofluid including effects of inclined magnetic field, Joule heating and thermal radiation. Discret. Contin. Dyn. Syst.-S 2020, 13, 2667. [CrossRef]

16. Ali Lunda, L.; Omara, Z.; Khan, I.; Sherif, E.S.M. Dual solutions and stability analysis of a hybrid nanofluid over a stretching/shrinking sheet executing MHD flow. Symmetry 2020, 12, 276. [CrossRef]

17. Mwesigye, A.; Huan, Z. Thermodynamic analysis and optimization of fully developed turbulent forced convection in a circular tube with water- $\mathrm{Al}_{2} \mathrm{O}_{3}$ nanofluid. Int. J. Heat Mass Transf. 2015, 89, 694-706. [CrossRef]

18. Ali Lunda, L.; Omara, Z.; Khan, I.; Seikh, A.; El-Sayed, H.; Sherif, M.; Nisar, K.S. Stability analysis and multiple solution of $\mathrm{Cu}-\mathrm{Al}_{2} \mathrm{O}_{3} / \mathrm{H}_{2} \mathrm{O}$ nanofluid contains hybrid nanomaterials over a shrinking surface in the presence of viscous dissipation. $J$. Mater. Res. Technol. 2020, 9, 421-432. [CrossRef]

19. Sohail, M.; Naz, R.; Abdelsalam, S.I. On the onset of entropy generation for a nanofluid with thermal radiation and gyrotactic microorganisms through 3D flows. Phys. Scr. 2020, 95, 045206. [CrossRef]

20. Aladdin, N.A.L.; Bachok, N.; Pop, I. Cu- $\mathrm{Al}_{2} \mathrm{O}_{3}$ / water hybrid nanofluid flow over a permeable moving surface in presence of hydromagnetic and suction effects. Alex. Eng. J. 2020, 59, 657-666. [CrossRef]

21. Kapen, P.T.; Ketchate, C.G.N.; Fokwa, D.; Tchuen, G. Linear stability analysis of $\left(\mathrm{Cu}^{-} \mathrm{Al}_{2} \mathrm{O}_{3}\right) /$ water hybrid nanofluid flow in porous media in presence of hydromagnetic, small suction and injection effects. Alex. Eng. J. 2021, 60, $1525-1536$.

22. Ilyas, H.; Ahmad, I.; Raja, M.A.Z.; Tahir, M.B.; Shoaib, M. Neuro-intelligent mappings of hybrid hydro-nanofluid Al2O3-Cu-H2O model in porous medium over rotating disk with viscous dissolution and Joule heating. Int. J. Hydrogen Energy 2021, 46, 28298-28326. [CrossRef]

23. Shaw, S. Impact of Cattaneo-Christov Heat Flux On $\mathrm{Al}_{2} \mathrm{O}_{3}-\mathrm{Cu} / \mathrm{H}_{2} \mathrm{O}-\left(\mathrm{CH}_{2} \mathrm{OH}\right)_{2}$ Hybrid Nanofluid Flow Between Two Stretchable Rotating Disks. In Energy Systems and Nanotechnology; Springer: Singapore, 2021; pp. 329-368.

24. Forchheimer, P.H. Wasserbewegung durch boden. Z. Ver. Deutsch. Ing. 1901, 45, 1782-1788.

25. Muskat, M. The Flow of Homogeneous Fluids Through Porous Media; McGraw-Hill: New York, NY, USA, 1946.

26. Saif, R.S.; Hayat, T.; Ellahi, R.; Muhammad, T.; Alsaedi, A. Darcy-Forchheimer flow of nanofluid due to a curved stretching surface. Int. J. Numer. Methods Heat Fluid Flow 2019, 29, 2-20. [CrossRef] 
27. Rasool, G.; Shafiq, A.; Khalique, C.M.; Zhang, T. Magnetohydrodynamic Darcy-Forchheimer nanofluid flow over a nonlinear stretching sheet. Phys. Scr. 2019, 94, 105221. [CrossRef]

28. Sadiq, M.A.; Haider, F.; Hayat, T.; Alsaedi, A. Partial slip in Darcy-Forchheimer carbon nanotubes flow by rotating disk. Int. Commun. Heat Mass Transf. 2020, 116, 104641. [CrossRef]

29. Sheikholeslami, M.; Arabkoohsar, A.; Ismail, K.A.R. Entropy analysis for a nanofluid within a porous media with magnetic force impact using non-Darcy model. Int. Commun. Heat Mass Transf. 2020, 112, 104488. [CrossRef]

30. Hayat, T.; Khan, S.A.; Alsaedi, A.; Fardoun, H.M. Heat transportation in electro-magnetohydrodynamic flow of DarcyForchheimer viscous fluid with irreversibility analysis. Phys. Scr. 2020, 95, 105214. [CrossRef]

31. Hayat, T.; Haider, F.; Alsaedi, A. Darcy-Forchheimer flow with nonlinear mixed convection. Appl. Math. Mech. 2020, 41, 1685-1696. [CrossRef]

32. Kumar, K.G.; Rahimi-Gorji, M.; Reddy, M.G.; Chamkha, A.J.; Alarifi, I.M. Enhancement of heat transfer in a convergent/divergent channel by using carbon nanotubes in the presence of a Darcy-Forchheimer medium. Microsyst. Technol. 2020, 26, 323-332. [CrossRef]

33. Sheikh, N.A.; Ali, F.; Khan, I.; Gohar, M. A theoretical study on the performance of a solar collector $\mathrm{using}^{\mathrm{CeO}} \mathrm{O}_{2}$ and $\mathrm{Al}_{2} \mathrm{O}_{3}$ water-based nanofluids with inclined plate: Atangana-Baleanu fractional model. Chaos Solitons Fractals 2018, 115, 135-142. [CrossRef]

34. Alzahrani, A.K.; Ullah, M.Z.; Alshomrani, A.S.; Gul, T. Hybrid nanofluid flow in a Darcy-Forchheimer permeable medium over a flat plate due to solar radiation. Case Stud. Therm. Eng. 2021, 26, 100955. [CrossRef]

35. Hsiao, K.L. Combined electrical MHD heat transfer thermal extrusion system using Maxwell fluid with radiative and viscous dissipation effects. Appl. Ther. Engr. 2017, 112, 1281-1288. [CrossRef]

36. Bilal, M. Micropolar flow of EMHD nanofluid with nonlinear thermal radiation and slip effects. Alex. Eng. J. 2020, 59, 965-976. [CrossRef]

37. Khan, S.U.; Tlili, I.; Waqas, H.; Imran, M. Effects of nonlinear thermal radiation and activation energy on modified second-grade nanofluid with Cattaneo-Christov expressions. J. Therm. Anal. Calorim. 2021, 143, 175-1186. [CrossRef]

38. Gorla, R.S.R.; Sidawi, I. Free convection on a vertical stretching surface with suction and blowing. Appl. Sci. Res. 1994, 52, 247-257. [CrossRef]

39. Liao, S.J. The Proposed Homotopy Analysis Method for the Solution of Nonlinear Problems. Ph.D. Thesis, Shanghai Jiao Tong University, Shanghai, China, 1992.

40. Liao, S.J. An optimal homotopy-analysis approach for strongly nonlinear differential equations. Commun. Nonlinear Sci. Numer. Simul. 2010, 8, 2003-2016. [CrossRef]

41. Zhao, Y.L.; Liao, S.J. Advances in the Homotopy Analysis Method, Chapter 7; World Scientific Press: Singapore, 2013.

42. Gul, T.; Ferdous, K. The experimental study to examine the stable dispersion of the graphene nanoparticles and to look at the GO-H2O nanofluid flow between two rotating disks. Appl. Nanosci. 2019, 8, 1711-1728. [CrossRef]

43. Sohail, M.; Shah, Z.; Tassaddiq, A.; Kumam, P.; Roy, P. Entropy generation in MHD Casson fluid flow with variable heat conductance and thermal conductivity over nonlinear bi-directional stretching surface. Sci. Rep. 2020, 10, 12530. [CrossRef] [PubMed]

44. Wang, C.Y. Free convection on a vertical stretching surface. ZAMM-J. Appl. Math. Mech. Z. Angew. Math. Mech. 1989, 69, 418-420. [CrossRef] 